\title{
Editorial
}

\section{Special Issue: Supporting University Students with Disabilities - Innovations, Strategies, and Practices that Achieve Results}

Over the past few decades, globalization has brought about many changes to the education environment, such as enhanced aspirations and increased opportunities to participate in tertiary education. Tertiary study is encouraged at many levels: from individuals and their families pursuing future success and prosperity; to ministries of education within governments that are tasked, among other things, with raising the skills and capabilities, productivity, and international competitiveness of their country's citizens [see, e.g., 1-4]. Incorporated in the ever-increasing numbers that are entering tertiary studies are nontraditional students. These include those who are less academically inclined and enrolling in more work skills-based qualifications that are now available in many universities (as well as in polytechnics, institutes of technology, and TAFE technical and further education - colleges where they had traditionally been offered); international students for whom the knowledge and experiences acquired from other countries might provide an advantage for future career prospects; mature students who have re-evaluated the relevance and desirability of tertiary education for themselves; returning students seeking further qualifications to improve promotional prospects or take on new directions in their careers; and students who have various forms of disabilities who, by their very participation, are contributing to dispelling the notions of disabilities on what an individual can achieve [see, e.g., 5-11].

To varying degrees, universities and tertiary institutions worldwide are taking steps to remove barriers that hinder the success of these non-traditional students. Such efforts include the provision of resources and support mechanisms aimed at alleviating disadvantages these students may experience, and the re-examination of educational views and teaching approaches to facilitate the necessary developments toward greater inclusiveness. This Special Issue of The Open Rehabilitation Journal focuses on programs and strategies that enhance learning outcomes for students with various forms of disabilities or impairments.

The research literature on disability support has focused mainly on the visible or more obvious challenges faced by students with disabilities. These include reports on the implementation of strategies to facilitate mobility access, the provision of services for students with various forms of sensory impairment, the development of software to overcome or circumvent problems in access to or use of information - in essence, strategies that address minimizing the effects of physical and sensory impairments.

In contrast, there is little research literature about strategies that address issues or challenges in effective learning once students with disabilities are enrolled in tertiary studies. However, students' abilities to learn effectively directly impact on their educational outcomes - whether they decide to complete their studies and, subsequently, whether they pass or fail. Even with state-of-the-art facilities, students who find it difficult to learn, to produce the necessary coursework, or to satisfactorily demonstrate their learning in assessments, would be negatively impacted in terms of their confidence and sense of self-efficacy, their motivations to learn and to persist, and ultimately their perceptions of the fit between tertiary education and themselves. From this perspective, attention to instruction and support services aimed directly at promoting more successful learning outcomes for students with disabilities ought to be a key priority, not just for researchers, but also for institutional service providers and decision makers in tertiary education. The Editors of this Special Issue, and the authors of the papers contained therein, hope that this publication will help stimulate attention to the research, as well as strategies development and implementation that are much needed in the area of learning support for tertiary students with disabilities.

The first three papers in this Special Issue deal with learning support for students with sensory impairments. The first paper by Matthew Brett (University of Melbourne, Australia) describes the provision of live remote captioning (LRC) for Deaf and hard of hearing students whose language support needs cannot be adequately met by sign language interpreting and notetaking services that are usually considered adequate in community and other educational contexts. The use of LRC has received highly positive feedback from staff and students alike and, since its piloted use at the University of Melbourne in 2006, is now used in at least 10 other universities in Australia. The second paper by Kate Chanock (La Trobe University, Australia) discusses the value of working collaboratively with students who have disabilities, in developing appropriate methods for learning support. The student described in the paper, who is Deaf-blind, actively worked with a learning advisor in determining the most appropriate strategies to support her learning - and subsequently demonstrated marked improvements in her academic work. Jawakhir Mior Jaafar and Mac Yin Mee (University of Malaya, Malaysia) emphasize the importance of open communication and discussion in formulating appropriate support strategies - this time, for Deaf students. Their paper details the efforts of one lecturer in attempting to meet the learning requirements of two graduate students with hearing impairments, the learning experiences that have ensued, and the students' progress in their respective course of study.

The remaining papers in this Special Issue deal with challenges in supporting students with various forms of hidden disabilities. Emmanuel Manalo, Jackie Ede, and Glenis Wong-Toi (University of Auckland, New Zealand) describe the provisions of a learning disabilities (LD) program at their university, and present its achievements in improving the learning outcomes for students with specific learning disabilities (SLD), attention deficit hyperactivity disorder (ADHD), mental health conditions, 
and other forms of hidden disabilities. Three case studies illustrate the ways in which learning advisors work with students to address their learning management and development needs. The following paper by Marcus Henning (University of Auckland, New Zealand) examines the benefits of using the Lucid Adult Dyslexia Screening (LADS), a computer screening system to identify the presence of SLD in university students. The author argues that the use of such a system enables timely and cost efficient identification of SLD, which in turn leads to more timely provision of accommodations to students when appropriate.

Marie Stevenson (University of South Australia, Australia) outlines practical strategies for working with university students with depression and anxiety disorders. The paper focuses on methods that academic learning advisors can employ to help these students to be more effective in the way that they manage and meet the demands of their courses of study. Finally, Kazunori Kakei (Showa University, Japan), Yuri Uesaka (Tokyo Institute of Technology, Japan), and Emmanuel Manalo (University of Auckland, New Zealand), deal with mental health support for Japanese university students suffering from apathy and other forms of mental health disorders. The paper argues that unique features of the Japanese cultural and social environment foster some unique mental health problems among the Japanese people, including identity development problems for many tertiary students. The paper describes the approach used in one university counseling center to help students overcome their mental health problems, and presents three case descriptions to illustrate support provisions for students with different categories of mental health disorders.

In providing instruction, skills training, and various forms of support for students, ongoing evaluation and development are indispensable, and sharing of best practice is one crucial way of facilitating these. If institutional and national aspirations in tertiary education achievement for wider sectors in society are to be met, greater effort is needed to promote learning about current and developing forms of practice - not just within our immediate vicinity but also more widely in other countries, especially as agreements in international student exchanges continue to become more desirable and popular. It is important to develop sound understanding of the ways in which certain strategies are effective, their possible adaptations and applications in other settings, their current limitations, and the ways in which they could be improved to achieve even better results. The Guest Editors of this Special Issue hope that publications such as this will help towards stimulating such sharing and learning: that more practitioners will be encouraged to write, that researchers will take genuine interest in examining the efficacy of the practices and innovations (perhaps in collaboration with practitioners), and that more of the policy and decision makers at both institutional and national levels, will take notice of the instruction and support methods that achieve tangible, positive outcomes for students.

This Special Issue would not have been possible without the help of many people. The Guest Editors sincerely thank the following colleagues who gave kindly of their time, knowledge and expertise to provide constructive feedback on manuscripts during the review process:

Ivan Beale (University of New South Wales, Australia)

Matthew Brett (University of Melbourne, Australia)

Kate Chanock (La Trobe University, Australia)

Libby Gordon Cohen (National Institute of Education, Singapore)

Marcus Henning (University of Auckland, New Zealand)

Masuo Koyasu (Kyoto University, Japan)

Steve Le Grow (Massey University, New Zealand)

David McKee (Victoria University of Wellington, New Zealand)

Rachel McKee (Victoria University of Wellington, New Zealand)

Patricia McLean (University of Melbourne, Australia)

John O'Connor (Auckland University of Technology, New Zealand)

Jane Rennie (University of Auckland, New Zealand)

Jitprapa Sri-on (Mahidol University, Thailand)

Shizuka Torii (two manuscript reviews; University of Auckland, New Zealand).

The Guest Editors are also grateful to the helpful and supportive staff of The Open Rehabilitation Journal, in particular Benish Ayaz Hassan, Saman Irfan, and Madiha Rauf.

\section{REFERENCES}

[1] James R. Non-traditional students in Australian higher education: Persistent inequities and the new ideology of 'student choice'. Tertiary Educ Manag $2000 ; 6: 105-18$

[2] Leathwood C, O'Connell P. 'It's a struggle': The construction of the 'new student' in higher education. J Educ Policy 2003; 18: 597-615. 
[3] Slaughter S, Leslie LL. Academic capitalism: Politics, policies, and the entrepreneurial university. Baltimore, MD: Johns Hopkins University Press 1997.

[4] Van-Rij-Heyligers J. Globalisation and pluri-scalar orchestrations in higher education: Locating the University of Auckland's Student Learning Centre historically and globally. Unpublished EdD thesis, The University of Auckland, New Zealand 2005.

[5] Bhandari R, Chow P. Open doors 2008: Report on international educational exchange. New York: Institute of International Education 2008.

[6] Cantwell R, Archer J, Bourke S. A comparison of the academic experiences and achievement of university students entering by traditional and nontraditional means. Assess Evaluat High Educ 2001; 26: 221-34.

[7] Hayes K, King E, Richardson J. Mature students in higher education: III. Approaches to studying in access students. Stud High Educ 1997; $22: 19-31$.

[8] Henderson C. College freshmen with disabilities: A biennial statistical profile. Washington DC: Heath Resource Center 2001.

[9] Kirby JR, Silvestri R, Allingham BH, Parrila R, La Fave CB. Learning strategies and study approaches of postsecondary students with dyslexia. J Learn Disabil 2008; 41: 85-96.

[10] Paul S. Students with disabilities in higher education: A review of the literature. Coll Stud J 2000; 34: 200-10.

[11] Ryan J. Learning disabilities in Australian universities: Hidden, ignored, and unwelcome. J Learn Disabil 2007; 40: 436-42.

[12] Wolf LE. College students with ADHD and other hidden disabilities. Ann N Y Acad Sci 2001; 931: 385-95.

Emmanuel Manalo and Glenis Wong-Toi
(Co-Guest Editors)

The Student Learning Centre

The University of Auckland

Private Bag 92019

Auckland 1142

New Zealand

E-mails: e.manalo@auckland.ac.nz,emmanuel.manalo@gmail.com,g.wong-toi@auckland.ac.nz

(C) Manalo and Wong-Toi; Licensee Bentham Open.

This is an open access article licensed under the terms of the Creative Commons Attribution Non-Commercial License (http://creativecommons.org/licenses/by$\mathrm{nc} / 3.0 /$ ) which permits unrestricted, non-commercial use, distribution and reproduction in any medium, provided the work is properly cited. 